\title{
Tea asthma: response to specific and non-specific challenges
}

\author{
J LEWIS, W K C MORGAN \\ From the Division of Pulmonary Diseases, University of Western Ontario, University Hospital, London, \\ Ontario, Canada N6A 5A5
}

We recently were asked to see a patient with a history of "tea asthma." Although she had been off work for months without any occupational exposure, and in addition had neither symptoms nor signs when examined, a specific inhalation challenge with tea was positive. A histamine test carried out before the challenge with tea had been negative but when repeated 24 hours after specific challenge it had become positive.

\section{Case history}

The patient was a 43 year old woman who had worked for the same company for 25 years. During the eight years before being seen she had cleaned the machines that initially fill tea bags and then later seal them. A fine, yellowish brown dust composed of microscopic tea particles was generated during the bagging. At the end of each day, the machines and immediate surroundings were covered with a fine layer of tea dust. Her symptoms had started 11 months before being seen and consisted of shortness of breath along with intermittent wheezing. She had noted that during a ten day holiday she had been much better and her symptoms had completely disappeared, only to recur when she went back to work. On close questioning, she also stated that she felt better at weekends and worse while at work and had missed several days due to shortness of breath and wheezing. Before the onset of symptoms she had missed almost no time from work at all. She gave no history of allergies or asthma and there was no history of atopy. She had smoked about ten cigarettes a day for around 25 years but gave this up at the onset of her symptoms.

On examination, she appeared well. The chest, and indeed the whole examination, was completely normal. Her chest radiograph likewise showed no abnormalities. Routine spirometry showed a FVC of 3.05 1 ( $90 \%$ of the predicted) and a $\mathrm{FEV}_{1}$ of $2 \cdot 171(76 \%$ of the predicted). This yields a $\mathrm{FEV}_{1} / \mathrm{FVC}$ of $71 \%$ which

Accepted 23 May 1988 is slightly below the predicted normal for her age.

A histamine challenge was negative, showing only a $\frac{\mathbb{D}}{3}$ slight fall in the $\mathrm{FEV}_{1}(12 \%)$ at $8 \mathrm{mg} / \mathrm{ml}$. Immediately thereafter she was given nebulised salbutamol and her $क$ $\mathrm{FEV}_{1}$ returned to $2.41 \mathrm{1}$. Two hours later she was $\underset{\omega}{\omega}$ challenged with finely powdered dextrose which of produced no response. The challenge was then 0 repeated with tea dust. Both the dextrose and tea challenges were effected by having her sit in a small $\bar{z}$ room and dropping the dextrose and tea dust from one tray to another. Measurements of her $\mathrm{FEV}_{1}$ were $\overrightarrow{ }$ carried out at five minute intervals for the first $15 \%$ minutes and then at quarter of an hour intervals for ${ }^{\oplus}$ the next several hours. Before the tea challenge her $\mathrm{FEV}_{1}$ was 2.451 . Three hours after the challenge, her FEV $_{1}$ fell to 21 (an 18\% decrement). This was associated with tightness in her chest, but wheezes $\stackrel{2}{\circ}$ were not heard. After nebulised salbutamol, her FEV $\stackrel{\unrhd}{\unrhd}$ returned within minutes to 2.451 . She noted mild chest $\overrightarrow{\vec{P}}$ tightness over the night and had to use her salbutamol $\frac{}{3}$ inhaler. The next day the histamine challenge was repeated. Her initial FEV, was $2.011(74 \%$ of the predicted) and fell to 1.671 with the $2 \mathrm{mg} / \mathrm{ml}$ dose of histamine, thus inducating that she had an increase in $\frac{\mathbb{}}{7}$ her non-specific bronchial reactivity.

\section{Discussion}

Occupational asthma is best defined as variable airways narrowing causally related to exposure to a specific antigen in the workplace, be the latter dust, $\frac{D}{0}$ gas, vapour, or fume. ${ }^{12}$ The symptoms may occur shortly after exposure - that is, in the first $30 \mathrm{~min}-\stackrel{N}{N}$ utes - or may be delayed several hours, with the delay $N$ ranging from three to 16 to 24 hours. Once symptoms $N$ develop, they may take several weeks or longer to $\omega$ resolve. ${ }^{2}$ Difficulty may arise in distinguishing occupationally induced asthma from occupationally ${ }_{E}$ provoked asthma. For diagnostic, social, and $\Phi_{\overparen{D}}$ medicolegal purposes it is frequently important to confirm that the asthmatic attacks are related to $\frac{0}{0}$ exposure to a specific agent. Although skin testing may $\overrightarrow{\mathbb{D}}$ yield positive results, the reactions are frequently non- $\frac{\rho}{\circ}$ 
specific. Similarly, serial measurements of peak flow while at work, although helpful in providing circumstantial evidence, suffer from the drawback that there is substantial variability in peak flow and it is impossible to ensure that the patient does not deliberately "adjust" the results to match his history. The most reliable diagnostic test, and indeed the gold standard for the diagnosis of occupational asthma, is the demonstration of a change in airway calibre produced by the inhalation of the specific agent suspected of causing the symptoms. ${ }^{3}$

Differences of opinion arise as to the most useful criteria to establish a diagnosis of occupational asthma. Airway hyperreactivity is usually measured by the method described by Cockcroft et al, ${ }^{4}$ and involves the inhalation of increasing doses of histamine or methacholine. Non-specific airway reactivity is frequently present in patients with all forms of asthma, including occupational asthma. ${ }^{5}$ Cartier et al have shown that the severity of the late asthmatic response is related to the magnitude and duration of histamine bronchial responsiveness and have suggested that specific and non-specific bronchial reactivity result from the same mechanism - that is, inflammation and smooth mucle contraction. ${ }^{6}$ Non-specific hyperresponsiveness, however, persists long after airflow obstruction has returned to normal. ${ }^{7}$ Alternative explanations must therefore be considered. Moreover, Burge and Hargreave et al have shown that occupational asthma may be present in the absence of increased sensitivity to histamine or methacholine, suggesting that different mechanisms account for the bronchial hyperreactivity in the two conditions. ${ }^{89}$

When a subject is challenged with the suspected agent and this induces changes in non-specific hyperreactivity in the absence of a change in airway calibre this presents a diagnostic problem. Some investigators have suggested that an increase in nonspecific airway reactivity after specific antigen challenge may be more sensitive and just as specific as changes in airway calibre. ${ }^{79}$ It has been suggested that despite the lack of change in airway calibre on specific challenge, increases in non-specific hyperreactivity after challenge with the suspected agent are significant and of diagnostic import. The basis for this assumption is somewhat tenuous. Our patient, who has a rare form of asthma and who had been separated for some considerable time from exposure to the antigen, had normal bronchial hyperreactivity before specific challenge. She had, however, retained her sensitivity to tea dust. The following day when the histamine challenge test was repeated a pronounced increase in her non-specific reactivity had developed.

It is clear from Chan-Yeung's studies that the severity and persistence of asthma are related to the persistence and severity of non-specific bronchial hyperreactivity. ${ }^{2}$ It is doubtful, however, whether affected subjects ever lose their specific sensitivity to the antigen. Thus there are reports of people who have had no exposure for many years and when they subsequently undergo a specific challenge show a definite decrease in $\mathrm{FEV}_{1}$ or similar index of airflow obstruction. ${ }^{2}$ For the present it is suggested that the gold standard for the diagnosis of occupational asthma must remain inhalational challenge with the suspected agent. A non-specific increase in bronchial hyperreactivity in the absence of changes in airway calibre may occur after non-specific challenge with various irritants ranging from ozone to aerosolised citric acid. ${ }^{1011}$

\section{References}

1 Newman-Taylor AJ. Editorial. Thorax 1980;35:241-5.

2 Chan-Yeung M, Lam S. Occupational asthma. Am Rev Respir Dis 1986;122:686-703.

3 Malo JL. Measurement of bronchial responsiveness in the investigation of asthma. In: Proceedings of symposium on impairment of men and women for work. Am Rev Respir Dis 1987;136:1052-3.

4 Cockcroft DW, Killian DN, Mellon JJA, Hargreave FE. Bronchial reactivity to inhaled histamine: a method and clinical survey. Clin Allergy 1977;7:235-43.

5 Lam S, Wong $R$, Yeung $M$. Nonspecific bronchial reactivity in occupational asthma. J Allergy Clin Immunol 1979;63:28-34.

6 Cartier A, Thomson NC, Frith PA, Roberts R, Tech M, Hargreave FE. Allergin-induced increase in bronchial responsiveness to histamine: relationship to the late asthmatic response and change in airway calibre. $J$ Allergy Clin Immunol 1982; 70: $170-2$.

7 Cartier A, L'Archeveuve J, Malo JL. Exposure to a sensitizing occupational agent can cause a long-lasting increase in bronchial responsiveness to histamine in the absence of significant changes in airway caliber. J Allergy Clin Immunol 1986;78: 1185-9.

8 Burge PS. Non-specific bronchial hyper-reactivity in workers exposed to toluene di-isocyanate, diphenylmethane di-isocyanate and colophony. Eur J Respir Dis 1982;123 (suppl):91-6.

9 Hargreave FE, Ramsdale EH, Pugsley SO. Occupational asthma without bronchial hyperresponsiveness. Am Rev Respir Dis 1984;130:513-5.

10 Bar-Sela S, Schiveter DP, Kitt SR, Sosman AJ, Fink JN. Antigeninduced enhancement of bronchial reactivity. Chest 1985; 88:114-6.

11 Holtzman MJ, Cunningham JH, Shellar JR, Irsigeler GB, Nadel JA, Boushey HA. Effect of ozone on bronchial reactivity in atopic and nonatopic subjects. Am Rev Respir Dis 1979; 120:1059-67. 